\title{
How to weigh an elephant seal with one finger: a simple three-dimensional photogrammetric application
}

\author{
P. J. Nico de Bruyn ${ }^{1, *}$, Marthán N. Bester ${ }^{1}$, Alejandro R. Carlini ${ }^{2}$, \\ W. Chris Oosthuizen ${ }^{1}$ \\ ${ }^{1}$ Mammal Research Institute, Department of Zoology and Entomology, University of Pretoria, Pretoria 0002, South Africa \\ ${ }^{2}$ Departamento de Ciencias Biológicas, Instituto Antárctico Argentino, Cerrito 1248 (1010) Buenos Aires, Argentina
}

\begin{abstract}
Several studies have developed photogrammetric techniques for indirect mass estimation of seals. Unfortunately, these techniques are often narrowly delineated for specific field scenarios or species. Many require sophisticated, custom-designed equipment or analytical tools, limiting their applicability. We aimed to devise a photogrammetric technique for accurate volume/mass estimation of seals under a variety of field scenarios without manipulation of the animal and with minimal equipment. We used Photomodeler Pro 3-dimensional modelling software to estimate the mass of 53 weighed southern elephant seals Mirounga leonina. The method is centred on animal volume estimation in relation to the 3-dimensional area around it, rather than features of the animal itself, an approach that liberates limitations associated with earlier studies. No morphometric body measures are required for such volume/mass estimation. We offer predictive equations that allow high confidence in mass estimates relative to measured mass $(95 \%$ confidence interval of mean deviation from measured mass is from \pm 1.34 to $\pm 3.83 \%$ depending on the field scenario). A single photographer with a measuring stick and non-customised digital photographic equipment can use this technique to determine the mass of an elephant seal anywhere in the field with the push of a button.
\end{abstract}

KEY WORDS: Southern elephant seal - Mass estimation ' Volume estimation - Body size · Field method $\cdot$ Photography $\cdot$ Life history $\cdot$ Phocids

\section{INTRODUCTION}

Body size of vertebrates (including related characteristics such as body mass) is a central theme in studies investigating geographical scaling patterns, physiological, behavioural and life-history parameters of individuals and populations (Peters 1983). Body mass estimation of terrestrial and marine mammal species are regularly based on scaling procedures of various body measurements (e.g. Bryden 1969, Christiansen 1999), and Trites \& Pauly (1998) observed strong linearity when maximum body lengths of 17 marine mammal species were plotted against mean individual masses. The ubiquitous terrestrial phase of pinniped species and their cumbersome movement on land, as compared with large, truly terrestrial mammals, have prompted biologists to use pinnipeds (more so than other mammalian groups) as study subjects to attempt body mass predictions based on morphological features.

Given the scaling relationships between morphological measures and body size/mass, various photogrammetric techniques (the use of photographs to measure objects) have been used to determine diverse morphological measures of mammals; these techniques include shoulder height and back length of African elephants Loxodonta africana (Hall-Martin \& Rüther 1979, Schrader et al. 2006), dorsal fin analyses of killer whales Orcinus orca (Keith et al. 2001) and baleen rack shape and size in bowhead whales Balaena mysticetus (Lambertsen et al. 2005). In pinnipeds, Haley et al. 
(1991) initiated photogrammetric use for body mass estimation in northern elephant seals Mirounga angustirostris, while Bell et al. (1997) applied a combined photogrammetric and morphometric technique of estimating body mass in southern elephant seals Mirounga leonina. However, the constraints under which current methods of photogrammetry can be used to accurately estimate seal mass are rigid. Animals have to be on a completely flat surface (e.g. hard/packed sandy beach), lying straight in ventral recumbency with no tolerance for movement, and the images captured when the animal has inhaled completely (Haley et al. 1991, Bell et al. 1997). The photographer is required to know the exact distance between the camera and the seal and scaling measure. More recently, Ireland et al. (2006) and Waite et al. (2007) made significant advances using new technology to estimate the masses of Weddell seals Leptonychotes weddellii and Steller sea lions Eumetopias jubatus, respectively. These methods have increased the accuracy of mass estimation for the particular species, but introduced (or maintained) various constraining field procedures, restricting their use in the field. The Ireland et al. (2006) method requires customised photographic equipment that is bulky and impractical in situations where the only method of traversing large distances between study subjects is by walking. Proffitt et al. (2008) successfully improved the photogrammetric mass estimation and confidence of the Ireland et al. (2006) procedure, by post hoc body form analysis using elliptical Fourier decomposition. However, the study did not simplify the field photographic component. The Waite et al. (2007) technique required sophisticated targeting on the seal and synchronized images from different angles to allow the 3-dimensional modelling of the subjects and required best estimates to remain morphologically correlated. Thus, all these methods require physical contact with the animal to acquire a morphometric measure or to manipulate posture. Restricted accessibility to haul-out locations, uneven substrates at haul-out sites, adverse weather conditions, and the behaviour of wild seals render all of these methods largely unsuitable for extensive and simple field implementation.

We report on a novel 3-dimensional photogrammetric field technique for mass estimation of pinnipeds without many of the abovementioned constraints. This technique is based on a volumetric estimation method that requires only one photographer with a digital camera and a calibrated measuring stick in the field. The technique was developed with the logistical challenges of isolated study areas and with varying substrate topography in mind. Additionally, analyses can be performed with a non-customised commercially available software package.

\section{MATERIALS AND METHODS}

Study area. The present study was conducted through several seasons between April 2006 and February 2008 at Antarctic-maritime Bouvetøya (BVT) (54² $5^{\prime} \mathrm{S}$, $\left.03^{\circ} 20^{\prime} \mathrm{E}\right)$, Stranger Point on King George Island (KGI) in the South Shetlands $\left(62^{\circ} 14^{\prime} \mathrm{S}, 58^{\circ} 40^{\prime} \mathrm{W}\right)$ and subAntarctic Marion Island (MI) (46 $\left.54^{\circ} \mathrm{S}, 37^{\circ} 45^{\prime} \mathrm{E}\right)$. Beach topography varied considerably between the 3 localities and within each site, ranging from flat sandy or pebble strewn to heavily bouldered substrates, sometimes covered in kelp and/or snow and ice, i.e. heterogeneity in beach topography that severely negates the use of existing photogrammetric techniques.

Field techniques. Fifty-three southern elephant seals Mirounga leonina of both sexes and varying age classes (Table 1) were weighed and photographed according to the procedures set out below.

Weighing procedure: Animals at MI and KGI were immobilised using an intramuscular dose of ketamine hydrochloride (2.4 to $6.2 \mathrm{mg} \mathrm{kg}^{-1}$ estimated body weight) (Bester 1988), while animals at BVT were immobilised using an intravenous dose of zolazepam: tiletamine (1:1) (Zoletil; $0.5 \mathrm{mg} \mathrm{kg}^{-1}$ ) after temporary restraint of the seal using the canvas head-bag technique (McMahon et al. 2000). Animals were then weighed in either a net stretcher or a broad strapping suspended from a load cell (different manufacturers depending on the location), attached to a block-andtackle and suspended from either a steel, aluminium, or carbon-fibre tripod. Seal mass $( \pm 0.5 \mathrm{~kg})$ was corrected in all cases for additional mass resulting from nets or strapping. Scales were calibrated with a known mass between weightings. Standard length measurements were taken for each animal while in ventral recumbency (Bonner \& Laws 1993).

Photographic procedure: Following weighing, each animal was photographed between 8 and 10 times from several different angles and heights (Fig. 1). The

Table 1. Mirounga leonina. Number of southern elephant seals, in each age and sex class, included in the present study. The mean body mass and range within each class are shown

\begin{tabular}{|c|c|c|c|c|c|}
\hline \multirow[t]{2}{*}{ Sex } & \multirow{2}{*}{$\begin{array}{c}\text { Age } \\
\text { category }\end{array}$} & \multirow{2}{*}{$\begin{array}{l}\text { Age } \\
\text { (yr) }\end{array}$} & \multirow{2}{*}{$\begin{array}{c}\text { No. } \\
\text { animals }\end{array}$} & \multicolumn{2}{|c|}{ Body mass (kg) } \\
\hline & & & & Mean & (Range) \\
\hline \multirow[t]{4}{*}{ Male } & Underyearling & $<1$ & 2 & 145 & $(140-149)$ \\
\hline & Yearling & 1 & 0 & & - \\
\hline & Juvenile & $2-3$ & 12 & 314 & $(212-387)$ \\
\hline & Subadult & $4-5$ & 11 & 443 & $(348-569)$ \\
\hline \multirow[t]{4}{*}{ Female } & Underyearling & $<1$ & 0 & & - \\
\hline & Yearling & 1 & 2 & 166 & $(132-200)$ \\
\hline & Juvenile & 2 & 7 & 226 & (163-269) \\
\hline & Adult & $>3$ & 19 & 431 & $(295-636)$ \\
\hline Total & & & 53 & 359 & $(132-636)$ \\
\hline
\end{tabular}


placement of camera stations (i.e. the approximate angle relative to the animal from which the photograph was taken) was roughly standardised (Fig. 1), but exact distances from the seal or measuring stick need not be known. A Canon EOS350D digital SLR camera (high resolution: 8 megapixels), with $18 \mathrm{~mm}$ Canon lens was used for photography at MI and BVT, while a Samsung Digimax 201 compact digital camera (medium resolution: 2 megapixels) at an EXIF focal length of $5.6 \mathrm{~mm}$ was used at KGI. An independent project was done for each of the 53 seals, and either one or the other camera was used per project. A single photographer circling the seal took the photographs.
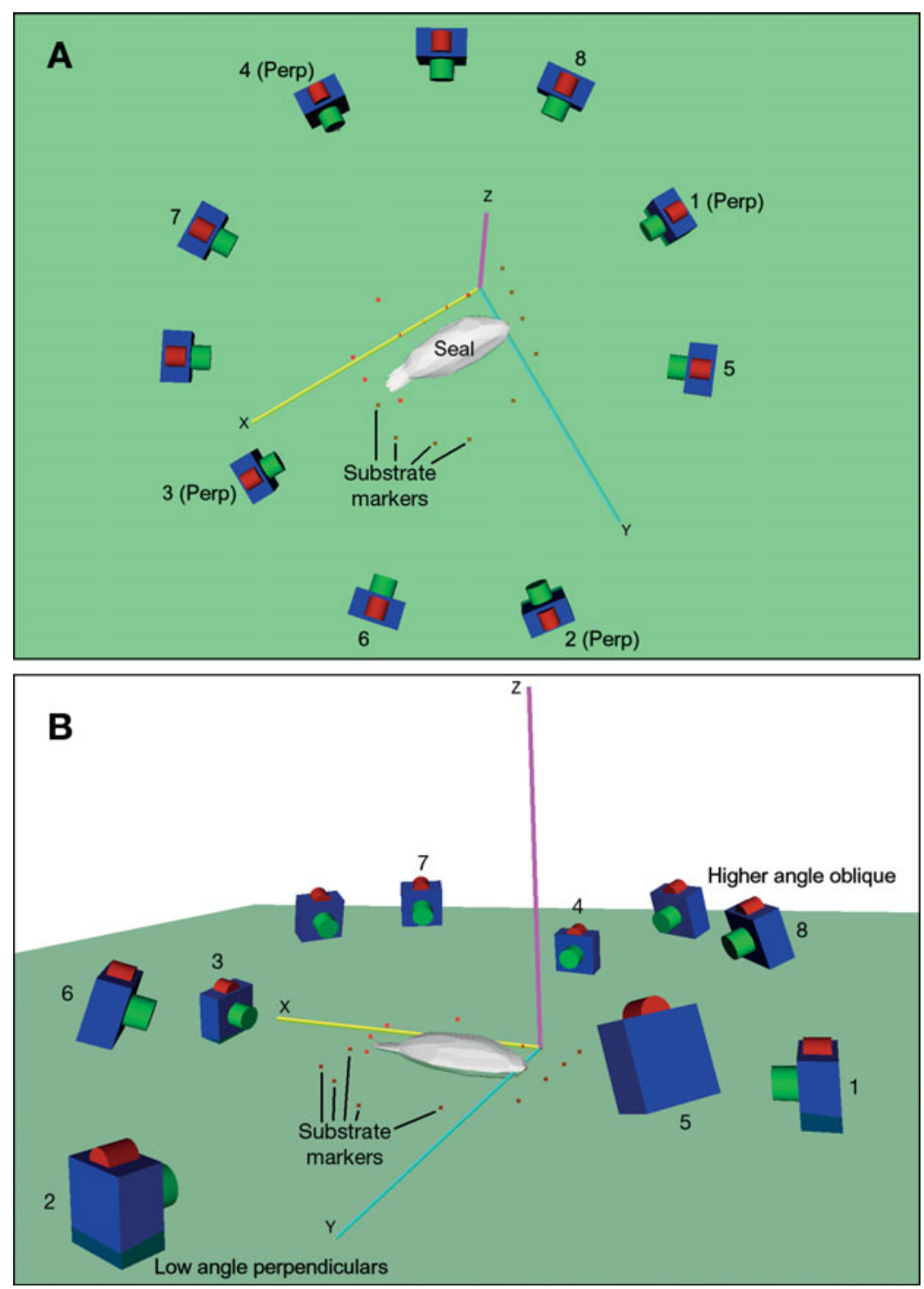

Fig. 1. (A: top view) Placement of camera stations (positions from which the photographs are taken) around the object to be modelled; (B: side view) photographs should be taken at varying heights around the object. Note the placement of the low-angle perpendicular (Perp) cameras. Numbered camera station: most important photographing positions for best estimates
Miscellaneous objects (5 to 15 ; e.g. tags, tag applicators, etc.) were randomly distributed on the substrate immediately around the seal as landscape/substrate markers (in addition to natural markers such as stones). Importantly, these markers remained unmoved during photography. A calibrated measuring stick, $150 \mathrm{~cm}$ in length, was placed somewhere amongst the markers to provide a scaling measure and also remained unmoved. The whole seal, markers and measuring stick were included in each photograph where the camera station allowed. Providing that the measuring stick/each marker was entirely visible in at least 3 of the photographs in a project, the seal in the foreground obscuring markers and/or measuring stick behind it was acceptable. Given the objective of providing a photogrammetric method with tolerance for seals resting on a variety of substrates (for applicability in the natural scenario), the substrate on which the animal was resting was categorised as either even (flat) or uneven (rough). Even surfaces had no depressions or protuberances (rocks), and a flat plane had little or no curvature under the seal (e.g. a hard sandy or finely pebbled beach). Uneven substrates had significant depressions or protuberances under the seal (such as a rocky/boulder beach, undulating moult wallow, or deep kelp bed), which may displace or 'swallow' some of its volume. On uneven substrates, the seal can thus be classified as not having a uniform planar surface where its body is in contact with the substrate. The body posture of seals was not manipulated for photographic purposes, and subjects were left undisturbed to assume a position of choice after the weighing procedure.

Photogrammetric analyses. Volumetric estimation: Volumetric estimation procedures were performed using the commercially available 3-dimensional (3D) modelling software package, Photomodeler Pro Version 6.2 (EOS Systems Inc.). In an independent, stringent evaluation of this software, Deng \& Faig (2001) confirmed the high level of accuracy in the creation of the relevant 3D space, justifying its use especially for digital close-range (i.e. not remote sensing) photogrammetry. The initial step (prior to fieldwork) is to individually calibrate each camera (and 
relevant lens combination) using the procedure and test pattern provided by the software. The program requires calibration resulting in known focal length of the lens, the digitizing scale (the charge-coupled device [CCD] format size of a digital camera), the principal point (where the optical axis of the lens intersects the photograph) and the parameters that describe the distortion characteristics of the lens. Following camera calibration, the photographer need not know the distance from the object, and each camera station can be randomly placed at various distances (and heights) around the object. This provides the option for using images from different non-identical cameras in one project provided each camera is calibrated (see Photomodeler Pro help file). Calibration for each camera/ lens combination occurs only once before its first use.

We initially attempted to create a 3D model of each seal based on the technique used by Waite et al. (2007) for Steller sea lions, whereby orientation points on the seal are cross-referenced between photographs to create a 3D space. Our attempts at this method failed because, firstly, natural marks on seals are scarce and/or difficult to identify for cross-referencing between photographs, and, secondly, seals (even when immobilised) move when breathing or otherwise, resulting in slight shifts of orientation points between photographs. To surmount this problem, initial 3D model construction was shifted away from the seal and focussed on the inanimate elements of each photograph, the substrate landmarks. Points identified on substrate markers (natural or inserted) were then cross-referenced between photographs containing those points, to create a 3D space within which to continue the model construction. On average, 22 (range: 16 to 36) cross-reference points were used per individual project (e.g. Fig. 2) to orientate all photographs, although all points were not visible on all photographs in a project. The software requirements for maintaining minimum 'residual error (RMS)' of each point (below 5.0; see Photomodeler Pro help file) on each photograph were adhered to (see Graff \& Gharib 2008 for details of accuracy in point-based 3D volumetric measurement systems). Once all photographs were successfully orientated based on the cross-referenced substrate points and an acceptable (RMS < 5.0) 3D space created as a result, the scale measure was marked on this orientated substrate (Fig. 2). The object (seal) shape was subsequently modelled in this $3 \mathrm{D}$ space using the 'silhouette' method (Fig. 2) of object model construction (see Photomodeler Pro help file). In the case of visual obstruction of a part of the seal, e.g. by rocks in the foreground of the photograph, the imaginary outline was followed. If $>30 \%$ of the seal was obstructed from view, the photograph was discarded.

Seal silhouettes were sequentially traced for each photograph (1 silhouette photograph ${ }^{-1}$ ), and volumetric estimates were obtained after the addition of each silhouette, starting at 3 silhouettes (the minimum needed to create a shape) through to 10 silhouettes, to test if volume estimates reached an asymptote after the addition of a specific number of photographs (camera stations) to the project. The Photomodeler Pro measuring tool was used to assign a scaling measure to the project based on the measuring stick in the photographs. To test if morphometric measures of the seal should be used as a scaling measure to improve ultimate estimates (see Waite et al. 2007), we marked the standard length of the seal on the photographs, assigned this as the scaling measure for the model, and compared the derived volumetric estimate with that gained from using the measuring stick in the image. Standard-length-scaled and measuring-stick-scaled volume estimates were compared for all 53 projects.

We extended/constricted some silhouettes in a project incorrectly (but realistically) to mimic head-, flipper-, or breathing-related movement between photographs and recalculated the volume estimates. Frontflippers were not included in the silhouette outline,

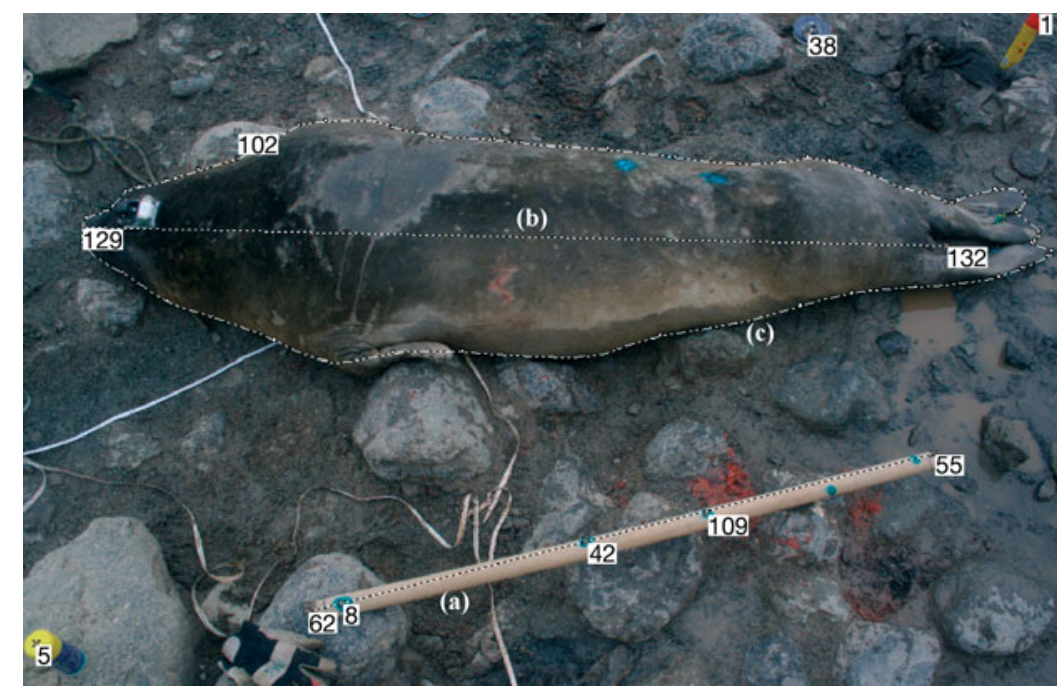

Fig. 2. Image of a southern elephant seal depicting the 2 scaling measures used separately for calculation of volume: a measuring stick (a) or standard length (b). Note the silhouette line (c) traced on the outline of the seal, which has been cross-referenced with similar silhouettes traced around the same animal on other photographs. Substrate markers (randomly numbered) have been used to create a 3-dimensional space, by cross-referencing these points with the same points on other photographs 
but hind-flippers were. Front-flippers are easy to exclude by following the bodyline of the seal. Head and hind-flipper movement of up to $45^{\circ}$ (angle between 2 head positions in the same project) in any direction was mimicked, while some full inhalation silhouettes and some complete exhalation silhouettes were modelled in the same project. Totally immobile and 'movement-related' volume estimates were compared for 20 projects.

To test Photomodeler Pro's specification that projects with overall project RMS $<5.0$ are accurate, we reorientated 10 animals 3 times as separate projects to test whether variation in substrate cross-referencing quality (that may be caused by different users for example) caused variation in ultimate volume estimates.

Mass estimation: The volume estimates of each object gained from Photomodeler Pro were separately multiplied by 2 different density values to calculate the mass of each seal. Firstly, the annual haul-out cycle of southern elephant seals (Kirkman et al. 2001, 2003, 2004) and its effect on body composition (blubber vs. lean-mass) were considered. Mean percentage body blubber content for seals of different sexes and ages (Bryden 1972, Slip et al. 1992, Carlini et al. 1999, 2005, Field et al. 2005) were converted into a blubber to lean-mass density ratio based on the densities of blubber $\left(0.95 \mathrm{~kg} \mathrm{~m}^{-3}\right.$; Gales \& Burton 1987) and lean-mass (1.10 $\mathrm{kg} \mathrm{m}^{-3}$; Le Boeuf et al. 2000), and this ratio was applied to the volumetric estimates to obtain estimated mass. Secondly, a density of $1.01 \mathrm{~kg} \mathrm{~m}^{-3}$, the mean $\left( \pm 0.04 \mathrm{~kg} \mathrm{~m}^{-3}\right)$ total-body density for healthy mammals regardless of total body fat content (Durnin \& Womersley 1974, Wang et al. 1999), was used for mass estimation of all animals. Use of the latter broadly applicable density thus precluded judgement of the body condition of the seals.

Data analysis: The deviation in predicted mass to measured body mass (\% under- or overestimate, hereafter called percentage error) was calculated for all projects and was used to evaluate predicted mass estimates. Firstly, we determined the minimum number of photographs that a project should use by comparing volumetric estimates from projects spanning 3 to 10 photographs. Then we tested for differences in percentage error from projects using a measuring stick or a standard length morpho-measure scale (Fig. 2). We also compared the percentage error from different cameras, although we were not able to compare the effect of different cameras on the same subject. Since camera differences were non-significant, and the use of a measuring stick resulted in significantly lower deviation from measured mass (see 'Results'), we grouped data from all study sites and used data from measuring-stick-scaled projects only in subsequent analyses. We compared the percentage error for all projects based on a mean density of $1.01 \mathrm{~kg} \mathrm{~m}^{-3}$ and on a blubber-to-lean-mass density ratio as predicted by haul-out type. Using the best volume to mass density conversion factor, we computed the mean effect of missing a single perpendicular photograph, or missing photographs encompassing an entire side view $\left(180^{\circ}\right)$, compared to the full view model by deleting relevant photos from full view projects. We fitted a general linear model to evaluate the effects of animal sex, age class (juvenile, subadult, adult), haul-out type (winter, pre-moult, mid-moult, post-moult), head movement during photographs (present or absent), and substrate (even or uneven) on predicted mass estimates. All analyses were performed using STATISTICA 7.0 (StatSoft), except the linear model that was fitted in SAS 9.1 (SAS Institute). Data were tested for normality using Shapiro-Wilk's $W$-test. The deviation in predicted mass to measured mass (percentage error) is presented as means $\pm 95 \% \mathrm{CI}$, and probability values are considered statistically significant at $\mathrm{p} \leq 0.05$.

\section{RESULTS}

Our results indicate that confident (percentage error $95 \%$ CI from \pm 1.34 to $\pm 3.83 \%$ depending on the field scenario) mass estimates of southern elephant seals Mirounga leonina relative to measured mass can be obtained by the use of this method. A mean of $6 \mathrm{~min}$ (range: 2 to $10 \mathrm{~min}$ ) in field effort was required for photography of each of the 53 animals. On average, $50 \mathrm{~min}$ (range: 20 to $210 \mathrm{~min}$ ) were required by a user to create a 3D modelled space and object shape (i.e. 1 project).

\section{Volumetric estimation}

The same project cross-referenced anew (3 repeats) never provided identical project RMS values. However, in maintaining RMS $<5.0$ for each of the 3 projects, ultimate volumetric estimates of the seal shape between the 3 iterations varied only by a third of a percent (range: 0.02 to $0.28 \%$ ). Mean overall project RMS for individual projects $(\mathrm{N}=53)$ was 1.518 pixel units (range: 0.774 to 3.576 ).

The 'totally immobile' and mimicked 'movementrelated' volume estimates tested in 20 projects were identical. If the bulk of the body shifted more than $\sim 15 \mathrm{~cm}$ in any direction between photographs, the resulting 3D model was visibly affected, resulting in 'tolerance violation' (see Photomodeler Pro help file), and the software rendered the volume calculation unsolvable. 
Project volume estimates improved significantly with every additional silhouette (after 3) included in the model (dependent $t$-test, from 3 to 8 photographs, $\mathrm{p}<0.01$ ). An asymptote was reached at 8 photographs $\left(t_{(8-9 \text { photographs })}=0.35, \mathrm{p}=0.72 ; t_{(8-10 \text { photographs })}=-1.10\right.$, $\mathrm{p}=0.28$; Fig. 3). Adding additional photographs to an 8-image project (mean project silhouette volume 0.355 $\pm 0.033 \mathrm{~m}^{3}$ ), therefore, did not significantly improve volume estimates (mean project silhouette volume for 10-image project: $0.352 \pm 0.033 \mathrm{~m}^{3}$ ).

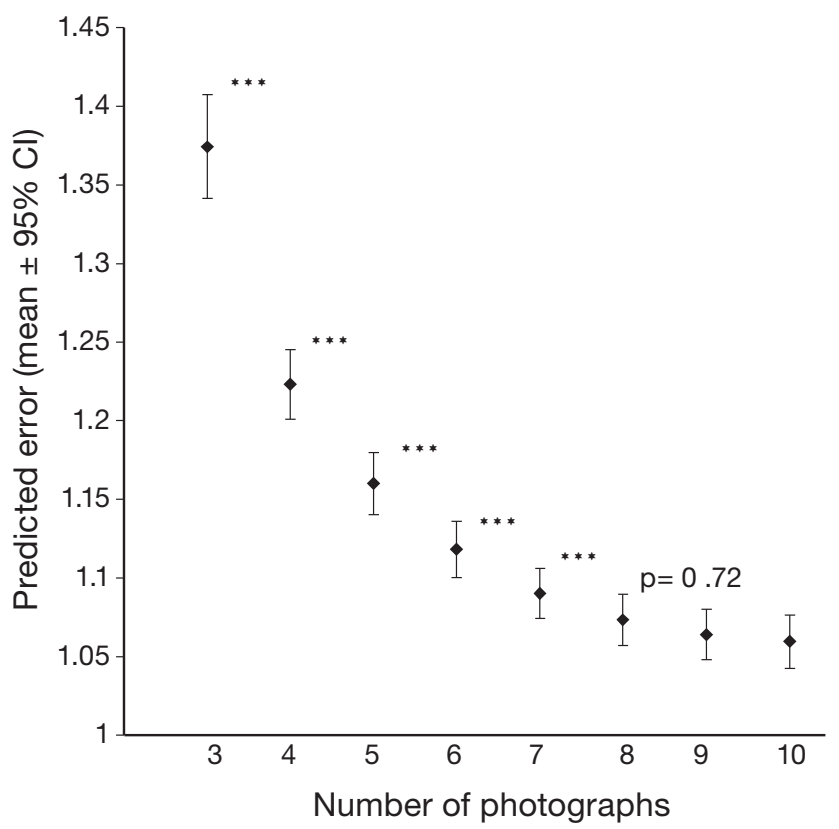

Fig. 3. Number of cross-referenced silhouettes (1 silhouette per photograph) required in Photomodeler Pro before an asymptote of volumetric estimation was approached. Volumetric accuracy increased significantly with addition of every silhouette up to 8 photographs in a project. ${ }^{* * *}$ Significant decrease in volumetric predicted error $(p<0.001)$

Table 2. Mirounga leonina. Predictive equations to approximate body mass of southern elephant seals. The full-view model depicts a minimum of 8 photographs, including all perpendiculars and all sides of the object (Fig. 1). $R^{2}$ values are the resultant linear regression fit of measured mass to predicted body mass for this dataset. PBM: predicted body mass $(\mathrm{kg})$; ME: mass estimate from photogrammetric volume $(\mathrm{kg})$

\begin{tabular}{|lccc|}
\hline Model & \multicolumn{1}{c}{ Equation } & $\mathrm{N}$ & $\mathrm{R}^{2}$ \\
\hline Even substrates: & & & \\
Full view & $\mathrm{PBM}=\mathrm{ME}-[\mathrm{ME} \times(0.085 \pm 0.013)]$ & 40 & 0.98 \\
Missing one perpendicular & $\mathrm{PBM}=\mathrm{ME}-[\mathrm{ME} \times(0.108 \pm 0.019)]$ & 31 & 0.97 \\
Missing an entire side view & $\mathrm{PBM}=\mathrm{ME}-[\mathrm{ME} \times(0.244 \pm 0.026)]$ & 40 & 0.96 \\
& & & \\
Uneven substrates: & $\mathrm{PBM}=\mathrm{ME}-[\mathrm{ME} \times(0.006 \pm 0.027)]$ & 13 & 0.98 \\
Full view & $\mathrm{PBM}=\mathrm{ME}-[\mathrm{ME} \times(0.004 \pm 0.038)]$ & 5 & 0.97 \\
Missing one perpendicular & $\mathrm{PBM}=\mathrm{ME}-[\mathrm{ME} \times(0.099 \pm 0.034)]$ & 13 & 0.97 \\
Missing an entire side view & $\mathrm{PBM}$ \\
\hline
\end{tabular}

\section{Mass estimation}

Mass estimates of full-view projects based on a measuring stick had less variation and were closer to measured mass $(9.71 \pm 1.27 \%)$ than those based on morphometric standard length measurements $(12.73 \pm 2.30 \%$; dependent $t$-test, $t_{104}=-2.78, \mathrm{p}<0.01$ ). The 2 different cameras used had similar percentage error estimates (Canon: $8.60 \pm 2.91 \%$; Samsung: $10.10 \pm 1.37 \%$; independent $t$-test, $t=-1.03, \mathrm{p}=0.31$ ). Model accuracy decreased significantly when the ratio density method was used compared to estimates based on a mean density of $1.01 \mathrm{~kg} \mathrm{~m}^{-3}$ (dependent $t$-test, $t_{52}=-36.48, \mathrm{p}<0.001$ ). The full-view model consistently overestimated measured mass $(6.59 \pm 1.52 \%)$. Overestimates of predicted mass increased further when a single perpendicular angle or an entire side view were deleted from projects, with the percentage error significantly higher than for the full model (repeated-measures ANOVA, $F_{2,70}=$ 203.46, p < 0.001) for both perpendicular $(9.36 \pm 2.09 \%)$ and missing side view $(20.83 \pm 2.72 \%)$ models (Tukey's HSD post hoc test for unequal sample sizes; $\mathrm{p}<0.01$ ). The variables included in the linear model explained little of the remaining variation in photogrammetric mass estimates $\left(F_{5,41}=4.69, \mathrm{p}=0.018, \mathrm{R}^{2}=0.36\right)$, with substrate type the only significant determinant (beta $=-8.25$, $F=17.78, \mathrm{p}<0.001)$. Even substrates resulted in an overestimate of predicted mass with narrow confidence intervals $(8.54 \pm 1.34 \%)$, while uneven substrates provided estimates close to the measured mass $(0.57 \pm 2.69 \%)$, albeit with greater variance.

\section{Predictive equations}

We applied equations to the predicted mass data (based on the mean percentage error) to adjust the mean overestimation of measured mass as estimated by this method (Table 2). All equations are dependent on the use of a measuring stick for volumetric scaling in the project and a mean density volumetric conversion factor of $1.01 \mathrm{~kg} \mathrm{~m}^{-3}$. $\mathrm{R}^{2}$ values were derived by plotting measured mass against predicted mass, and corrected mass using the appropriate equations (Fig. 4).

\section{DISCUSSION}

This photogrammetric mass estimation method centres on the accurate estimation of the volume of an object within a 3D space orientated by cross- 

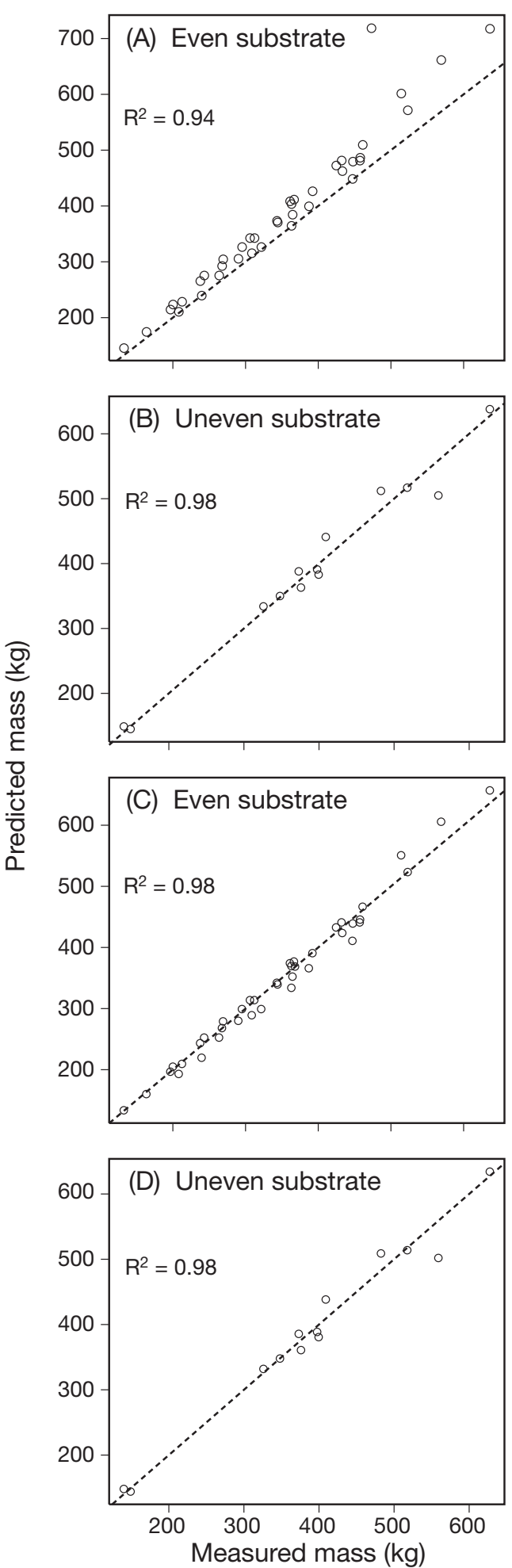

Fig. 4. Mirounga leonina. Regression of predicted body mass against measured body mass for southern elephant seals on even and uneven substrates. $(\mathrm{A}, \mathrm{B})$ Predicted mass values obtained from full-view photogrammetric projects; $(\mathrm{C}, \mathrm{D})$ predicted mass estimates multiplied by the appropriate correction factors given in Table 2. Dotted line: true regression line (intercept $=0$, slope $=1$ ) referencing of inanimate points surrounding this object. This approach ensures that the animate object to be modelled (the seals Mirounga leonina in our case) is not dependent on features of itself, but rather on the more stable substrate to create an accurate 3D space. This liberates many constraints associated with the modelling of an object (Proffitt et al. 2007, 2008), such as absolute immobility of the object, clearly recognisable 'landmarks', or measures on the object (morphometrics), and specific object postures or shapes (Haley et al. 1991, Bell et al. 1997, Ireland et al. 2006, Waite et al. 2007). In so doing, this 3D modelling procedure addresses our objective for simple photography of seals (without physical contact) on a variety of substrates without the need for sophisticated, bulky, or customdesigned equipment. Because cross-referenced silhouettes do not depend on accuracy measures of the silhouetted object, but rather on the surrounding substrate markers, slight movement of the object (and thus the marked silhouette), or object complexity, has a limited influence on ultimate project accuracy and the volume estimate. Thus, although an animal needs to be stationary, our results suggest some tolerance for movement (particularly of head or appendages). Additionally, this method diverges from the morphometricto-body-mass scaling procedures used to date. Firstly, it removes the constraint to immobilize and physically measure study subjects. It can therefore be used on stationary seals without the need to handle seals. Secondly, this method is not restricted to the scaling relationships of a specific species. In light thereof, it seems probable to determine the volume of a large mammal regardless of the species or surroundings, and to calculate the mass of a particular animal based on the narrow total-body density range applicable to mammals (Durnin \& Womersley 1974, Wang et al. 1999). However, our results are based only on southern elephant seals, and while the physics and functionality of the software and method suggest their applicability to other mammalian groups, their accuracy therein remain to be confirmed.

The immobility of the study subject when using this method is a by-product of the single photographers' need to circle the animal (for field application); however, the software provides the option for the processing of photographs depicting the same object but produced by different calibrated cameras. In projects where seals rested on highly uniform substrates (e.g. snow, sand), the addition of non-natural substrate markers (e.g. unique coloured marbles) around the seal reduced analysis time considerably (searching for natural markers required less time). Three iterations of 3D space construction for the same project did not produce identical results due to the difficulty (even for the same user) of placing a mark on exactly the same pixel in an image in 3 exclusive at- 
tempts. However, ultimate volumetric estimates of the seal shape between the 3 iterations (e.g. different users) remained negligible if software stipulations were adhered to (i.e. RMS < 5.0). No significant difference between the use of a medium- or high-resolution digital camera was evident in estimates. Consequently, one is not obliged to purchase expensive or sophisticated digital camera equipment to apply this method.

High- and low-angle photographs from camera stations around the subject (top views - Fig. 1, z-axis are especially useful, albeit not crucial) are critical for accurate model construction (de Bruyn pers. obs.). This is due to the silhouette method simply calculating the shape and size of an object from the silhouette projection algorithm when the silhouette is referenced on 3 or more orientated photographs. This effectively means that a missing side view results in an overestimation of the extent of the object on the opposite side of the missing camera stations, because camera stations are not sufficiently angled to allow the software to trim the model. This silhouette projection algorithm is also likely the cause for the difference in mass estimates between animals on even and uneven substrates. Because photographs of the object cannot be captured from a camera station exactly at/or lower than ground level, the 3D model based on silhouettes results in a convex, rather than a planar, lower surface for the object. The volume of an animal resting on an uneven substrate where some of its volume may in reality be 'swallowed' by a depression under it would therefore be more correctly modelled as having a convex lower surface. The greater variance around estimates for uneven surfaces results from not every animal on an uneven surface having a completely convex lower surface (e.g. sometimes it may be partially convex and partially concave due to uneven terrain). An animal resting on an even surface would, in reality, have a planar lower surface, but that would still be modelled as convex, resulting in the consistent overestimates (but with greater confidence) reported here. We provide predictive equations for field scenarios where an incomplete set of photographs is available (missing a side view due to a large boulder preventing camera stations on a specific side for example) for subjects resting on even or uneven substrates, but caution their use for high-accuracy mass estimations.

An added advantage of using the substrate point referenced 3D space method (present study) is that a measuring stick can be photographed on the substrate where the animal was situated, after its departure. These photographs are then orientated with those in which the subject is present to provide a scale to the project. Alternatively, a unique feature on the substrate can be measured after photographs were taken and included as the scaling measure. The significantly poorer performance of a morphometric measure as compared with an inanimate measure in the project results from the inability to accurately mark standard length on animals in the photographs. This could be due to some points of the animal (such as the tail tip) not being visible on photographs, movement of the head resulting in error when the apex of the nose is cross-referenced, or the posture of the animal.

The technique can greatly assist longitudinal studies (de Bruyn et al. 2008) that would traditionally have required reweighing of marked animals (Fedak \& Anderson 1987). It reduces limitations for mass estimation under the following criteria: (1) use of a calibrated digital camera, (2) by taking at least 8 photographs around the stationary animal (Fig. 1) and including sufficient substrate in each photograph to facilitate point identification, and (3) by including a measuring stick (preferably $>1.5 \mathrm{~m}$ in length for large mammals) in at least 3 of the 8 photographs.

Acknowledgements. J. Hargrave and EOS Systems Inc. are thanked for their valuable input, W. N. Wilke provided technical assistance early in the present study, and we are indebted to the Marion Island 63rd and 64th expedition teams for their support, with special thanks to C. A. Tosh. The 5th Bouvetøya and the 2007/2008 Argentine Antarctic expedition teams assisted in the field, and J. Negrete helped with photography on KGI. The Department of Environmental Affairs and Tourism provided logistical support (for Marion and Bouvet Islands) within the South African National Antarctic Programme, while the Dirección Nacional del Antártico provided logistic support at KGI. The Norwegian Polar Institute allowed the work on Bouvetøya. The Department of Science and Technology, through the National Research Foundation (South Africa), financed the project, while P.J.N.d.B. benefited from a National Research Foundation Grantholderlinked doctoral bursary within the project 'Conservation of Seabirds, Shorebirds and Seals' that funds a consortium of researchers led by L. Underhill of the Animal Demography Unit, Department of Zoology, University of Cape Town. We thank 3 anonymous reviewers for their valuable input.

All procedures at MI have ethics clearance from the Animal Use and Care Committee (AUCC) of the Faculty of Veterinary Science, University of Pretoria, South Africa, under AUCC 040827-023. The procedures at KGI were approved by the Argentinean Dirección Nacional del Antártico (environmental office), while the Norwegian National Animal Care Authorities regulations were followed for the work on Bouvetøya.

\section{LITERATURE CITED}

Bell CM, Hindell MA, Burton HR (1997) Estimation of body mass in the southern elephant seal, Mirounga leonina, by photogrammetry and morphometrics. Mar Mamm Sci 13: 669-682

Bester MN (1988) Chemical restraint of Antarctic fur seals and southern elephant seals. S Afr J Wildl Res 18:57-60

Bonner WN, Laws RM (1993) Morphometrics, specimen collection and preservation. In: Laws RM (ed) Antarctic seals: 
research methods and techniques. University Press, Cambridge, p 161-171

Bryden MM (1969) Growth of the southern elephant seal, Mirounga leonina Linn. Growth 33:69-82

Bryden MM (1972) Body size and composition of elephant seals (Mirounga leonina): absolute measurements and estimates from bone dimensions. J Zool 167:265-276

Carlini AR, Marquez MEI, Daneri GA, Poljak S (1999) Mass changes during their annual cycle in females of southern elephant seals at King George Island. Polar Biol 21: 234-239

> Carlini AR, Daneri GA, Marquez MEI, Bornemann H and others (2005) Food consumption estimates of southern elephant seal females during their post-breeding aquatic phase at King George Island. Polar Biol 28:769-775

Christiansen P (1999) Scaling of the limb long bones to body mass in terrestrial mammals. J Morphol 239:167-190

de Bruyn PJN, Tosh CA, Oosthuizen WC, Phalanndwa MV, Bester MN (2008) Temporary marking of unweaned southern elephant seal (Mirounga leonina L.) pups. S Afr J Wildl Res 38:133-137

Deng G, Faig W (2001) An evaluation of an off-the-shelf digital close-range photogrammetric software package. Photogramm Eng Remote Sensing 67:227-233

Durnin JVGA, Womersley J (1974) Body fat assessed from total body density and its estimation from skinfold thickness: measurements on 481 men and women aged from 16 to 72 years. Br J Nutr 32:77-97

Fedak MA, Anderson SS (1987) Estimating the energy requirements of seals from weight changes. In: Huntley AC, Costa DP, Worthy GAJ, Castellini MA (eds) Approaches to marine mammal energetics. Allen Press, Lawrence, KS, p 206-226

Field IC, Bradshaw CJA, Burton HR, Hindell MA (2005) Juvenile southern elephant seals exhibit seasonal differences in energetic requirements and use of lipids and protein stores. Physiol Biochem Zool 78:491-504

- Gales NJ, Burton HR (1987) Ultrasonic measurement of blubber thickness of the southern elephant seal, Mirounga leonina (Linn.). Aust J Zool 35:207-217

Graff EC, Gharib M (2008) Performance prediction of pointbased three-dimensional volumetric measurement systems. Meas Sci Technol 19:075403

Haley MP, Deutsch CJ, Le Boeuf BJ (1991) A method for estimating mass of large pinnipeds. Mar Mamm Sci 7: 157-164

Hall-Martin AJ, Rüther H (1979) Applications of stereo photogrammetric techniques for measuring African elephants. Koedoe 22:187-198

Ireland D, Garrot RA, Rotella J, Banfield J (2006) Development and application of a mass-estimation method for Weddell seals. Mar Mamm Sci 22:361-378

Keith M, Bester MN, Bartlett PA, Baker D (2001) Killer whales

Editorial responsibility: Hans Heinrich Janssen,

Oldendorf/Luhe, Germany
(Orcinus orca) at Marion Island, Southern Ocean. Afr Zool 36:163-175

Kirkman SP, Bester MN, Pistorius PA, Hofmeyr GJG, Owen R, Mecenero S (2001) Participation in the winter haul-out by southern elephant seals (Mirounga leonina). Antarct Sci 13:380-384

Kirkman SP, Bester MN, Pistorius PA, Hofmeyr GJG, Jonker FC, Owen R, Strydom N (2003) Variation in the timing of moult in southern elephant seals at Marion Island. S Afr J Wildl Res 33:79-84

> Kirkman SP, Bester MN, Hofmeyr GJG, Jonker FC, Pistorius PA, Owen R, Strydom N (2004) Variation in the timing of the breeding haulout of female southern elephant seals at Marion Island. Aust J Zool 52:379-388

> Lambertsen RH, Rasmussen KJ, Lancaster WC, Hintz RJ (2005) Functional morphology of the mouth of the bowhead whale and its implications for conservation. J Mammal 86:342-352

Le Boeuf BJ, Crocker DE, Costa DP, Blackwell SB, Webb PM, Houser DS (2000) Foraging ecology of northern elephant seals. Ecol Monogr 70:353-382

- McMahon CR, Burton HR, McLean S, Slip D, Bester MN (2000) Field immobilisation of southern elephant seals with intravenous tiletamine and zolazepam. Vet Rec 146: 251-254

Peters RH (1983) The ecological implications of body size. Cambridge University Press, Cambridge

Proffitt KM, Garrott RA, Rotella JJ, Banfield J (2007) The importance of considering prediction variance in analyses using photogrammetric mass estimates. Mar Mamm Sci 23:65-76

> Proffitt KM, Garrott RA, Rotella JJ, Lele S (2008) Using form analysis techniques to improve photogrammetric massestimation methods. Mar Mamm Sci 24:147-158

Schrader AM, Ferreira SM, van Aarde RJ (2006) Digital photogrammetry and laser rangefinder techniques to measure African elephants. S Afr J Wildl Res 36:1-7

Slip DJ, Gales NJ, Burton HR (1992) Body mass loss, utilisation of blubber and fat, and energetic requirements of male southern elephant seals, Mirounga leonina, during the moulting fast. Aust J Zool 40:235-243

Trites AW, Pauly D (1998) Estimating mean body masses of marine mammals from maximum body lengths. Can J Zool 76:886-896

- Waite JN, Schrader WJ, Mellish JE, Horning M (2007) Threedimensional photogrammetry as a tool for estimating morphometrics and body mass of Steller sea lions (Eumetopias jubatus). Can J Fish Aquat Sci 64:296-303

Wang Z, Deurenberg P, Wang W, Pietrobelli A, Baumgartner RN, Heymsfield SB (1999) Hydration of fat-free body mass: review and critique of a classic body-composition constant. Am J Clin Nutr 69:833-841

Submitted: October 10, 2008; Accepted: December 16, 2008 Proofs received from author(s): January 26, 2009 